$14^{\text {th }}$ International Conference on

AEROSPACE SCIENCES \& AVIATION TECHNOLOGY,

ASAT - 14 - May 24 - 26, 2011, Email: asat@mtc.edu.eg

Military Technical College, Kobry Elkobbah, Cairo, Egypt

Tel: +(202) 24025292-24036138, Fax: $+(202) 22621908$

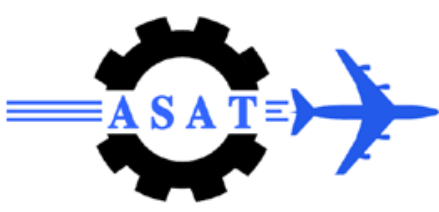

\title{
Practical Estimation of the Longitudinal and Lateral Hydrodynamic Coefficients of Underwater Vehicle by Free Decay Pendulum Motion
}

\author{
M. Fayed ${ }^{*}$, Adel Omer ${ }^{\dagger}$ and A.M. Badawy ${ }^{\ddagger}$
}

\begin{abstract}
A good dynamics mode 1 is e ssential a nd critical $\mathrm{f}$ or $\mathrm{d}$ ynamic a nalysis of underwater ve hicle. $\mathrm{H}$ owever, i t i s di fficult $t \mathrm{o}$ de termine $t$ he $h$ ydro-dynamics $f$ orces, especially the added mass and the drag coefficients. In this paper, an experimental method has been used $t \mathrm{o} f$ ind $t$ he $h$ ydrodynamics f orces f or a $r$ emotely ope rated underwater ve hicle (ROV). The proposed method is based on the classical free decay test. The experiment was video captured, then processed by a Covariance Tracking MATLAB ${ }^{\mathrm{TM}}$ computer program to determine $t$ he $t$ ime hi story of $t$ he $s$ winging a ngle of $t$ he $m$ odel, $t$ hen $t$ he va lues $w$ ere numerically processed by least s quare m ethod to determine the co efficients va lues, which compared $\mathrm{w}$ ith the $\mathrm{s}$ imulation results obt ained $\mathrm{f}$ rom $\mathrm{w}$ ell-established computational $\mathrm{f}$ luid dynamics (CFX) program. Thus, the proposed approach can be us ed to find the added mass and drag coefficients for other underwater vehicles.
\end{abstract}

Keywords: ROV, Hydrodynamic coefficients, Covariance Tracking, CFX, Least Square.

$\begin{array}{ll}\text { Nomenclature } \\ \mathrm{B} & \text { Buoyancy } \\ \mathrm{F}_{\mathrm{H}} & \text { Hydrodynamic force } \\ \mathrm{F}_{\text {rod }} & \text { Tension force from the rod } \\ \mathrm{G} & \text { Gravitational acceleration } \\ \mathrm{K}_{\mathrm{L}} & \text { Linear damping coefficient } \\ \mathrm{K}_{\mathrm{Q}} & \text { Quadric damping coefficient } \\ \mathrm{K}_{\mathrm{t}} & \text { Torsion spring constant } \\ \mathrm{M} & \text { Mass of the model } \\ \mathrm{M}_{\mathrm{a}} & \text { Added mass in single DOF } \\ \mathrm{R} & \text { Length of the pendulum (radius) } \\ \mathrm{V} & \text { Tangential velocity } \\ \Theta & \text { Angle of rotation of the pendulum }\end{array}$

\footnotetext{
*Egyptian Armed Forces, Egypt/ $m$ alghany@hotmail.com

† Egyptian Armed Forces, Egypt, Adelomer00@yahoo.com

† Egyptian Armed Forces, Egypt, ayman_mtc81@yahoo.com
} 


\section{Introduction}

Water covers $71 \%$ of plant earth, this fact leading us to the necessity of exploring this huge area $o f t$ he $p l$ ant $w$ hich $w$ ill be the f uture of $h$ umanity. Gathering da ta a nd studying the underwater environment is the first s tep to control and ha ve be nefits of the oc ean's wealth. Human can only dive to the depth near $300 \mathrm{~m}$ eters without solid suit or vehicle, while man can dive to the depth near 600 using a hard-shell suit.

Oil underwater pipe lines path from country to country through sea must go through depths more $t$ han $(600 \mathrm{~m})$, $\mathrm{t}$ hese 1 ines ne ed $\mathrm{t} \mathrm{o}$ be maintained a nd $\mathrm{r}$ epaired. $\mathrm{C}$ atastrophic $\mathrm{s}$ hip accidents cannot be ensured to happen in shallow water. Oil exploration in s eas and oc eans also leads to the same result, the necessity of remotely operated underwater vehicles.

In order $\mathrm{t} o$ establish an ROV $\mathrm{m}$ odel $\mathrm{i} \mathrm{t}$ i $\mathrm{s} \mathrm{n}$ ecessary $\mathrm{t}$ o de termine the $\mathrm{h}$ ydrodynamic coefficients of the structure which reflects the effects of the underwater environment on the ROV s tructure motion. A t ow tank tests of the ve hicle or a s cale model w as us ed by ( $\mathrm{P}$. Egeskov a nd C . A age) $[1,2]$. S pecial e quipment $\mathrm{c}$ alled pl aner m otion $\mathrm{m}$ echanism (PMM), where the model is forced to move in a tank in a planer motion and a system of force and moment s ensors are us ed to indicate these values while another set of sensors indicates the position in six degree of freedom, which give a complete model identification.

However $t$ he $t$ ow $t$ ank $t$ hat e quipped $w$ ith a $P$ MM i s ve ry costly. In a ddition, $t$ he $t$ est procedures are highly time-consuming. A. Alessandri, P. Ridao and D. A. Smallwood [3.4.5] used on-board s ensors to indicate the thrust force and pos ition identification, which is very helpful in ROV which vary its shape during mission, this method is also very costly and the repeatability is very high. However most of the works simplify the model to an uncoupled one DOF model, which needs the motion of the ROV to be constrained to a single DOF during identification. This is hard to implement in practice. In addition, it is also hard to model the thruster forces and to measure the vehicle's responses accurately.

The us e o f f ree de cay t est i $\mathrm{n}$ finding $\mathrm{t}$ he $\mathrm{h}$ ydrodynamics co efficients $\mathrm{w}$ as $\mathrm{r}$ eported $\mathrm{b} \mathrm{y}$ Morrison [6] in 1993. In his study, the hydrodynamics coefficients of the ROV Hylas were determined successfully for the he ave motion. The R OV Hylas w as allowed to os cillate in water by hanging it from an overhead crane by using three springs. The position of the Hylas was de termined us ing $\mathrm{S}$ onic $\mathrm{H}$ igh $\mathrm{A}$ ccuracy $\mathrm{R}$ anging and $\mathrm{P}$ ositioning $\mathrm{S}$ ystem (SHARPS). Free de cay test have al so been studied by T. I. F. A. R oss [7] to identify a mul tiple-DOF model of an UUV. In h is proposed experiment, the unde rwater ve hicle is a ttached to four springs. The method was tested using a computer simulation and the results converge to true values. The proposed free decay tests exhibit a few problems in practice. Firstly, the vehicle's positions are needed during identification and the main problem is the ability to measure the vehicle states accurately. In Morrison [6], this problem is solved by employing an expensive underwater positioning system (SHARPS). In T. I. F. A. Ross [7], only computer simulation is done. Secondly, all the springs must always be kept in tension during the oscillations. It is challenging $\mathrm{f}$ or $\mathrm{s}$ uch e xperiment $\mathrm{c}$ onfiguration $\mathrm{t} \mathrm{o} \mathrm{c}$ onstraint $\mathrm{t}$ he $\mathrm{R} \mathrm{OV} \mathrm{m}$ otion $\mathrm{w}$ ithin $\mathrm{t}$ he predefined DOF. As a result, the mathematical model may not represent the motion accurately and thus the identified results might be poor.

In $\mathrm{t}$ his pa per, $\mathrm{t}$ he $\mathrm{h}$ ydrodynamics a dded $\mathrm{m}$ ass a nd $\mathrm{dr}$ ag $\mathrm{f}$ orces $\mathrm{w}$ ill be de termined experimentally using a model (Fig 1) of the ROV. The model is set to oscillate in water when it is displaced from its equilibrium position and due to the hydrodynamics forces that resist the motion, the amplitude of the swing will decay over time. The hydrodynamics parameters can then be extracted from the time history of the motion, Eng YH, Lau W S, Low E., S eet 
GGL and C S C hin [8]. As the m odel is allowed to os cillate freely in the w ater t ank, the experiment is classified as a free decay test. Then, verification is performed by comparing the experimental values obtained with that predicted by CFX for the ROV. The proposed method has few advantages. Firstly, the motion of the pendulum is restricted in a plane and has only one $\mathrm{D}$ OF. $\mathrm{T}$ he pos ition of pe ndulum i $\mathrm{s} f$ ully described $\mathrm{b}$ y va riable $\theta$. $\mathrm{T}$ he $\mathrm{m}$ otion i $\mathrm{s}$ appropriately constrained and $h$ ence, the d ynamics e quation of m otion could $r$ epresent the motion correctly. Therefore, the result will be more accurate. Secondly, the variable $\theta$ can be measured easily using a potentiometer or an encoder. However, in this experiment, the angle $\theta$ is obtained through visual sensing using a di gital camera, then processed by a Covariance Tracking MATLAB ${ }^{\mathrm{TM}}$ computer program to determine the time history of the swinging angle of the model, then the values were numerically processed by least square method to determine the coefficients values. The method is very simple and reasonably accurate. As a whole, the experimental setup is simple and is very low cost compared with the building cost of a water tunnel facility with PMM equipment.

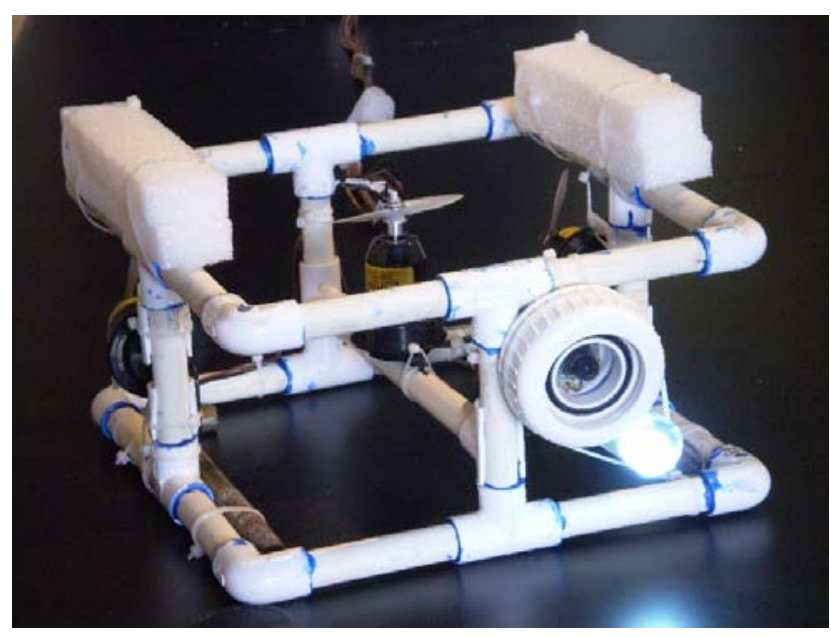

Fig. 1 ROV model

\section{Dynamics Equation}

Consider an object of interest attached at the end of the pendulum and fully submerged in the water. The object moves in a circular path with radius $r$ as shown in Fig 2.

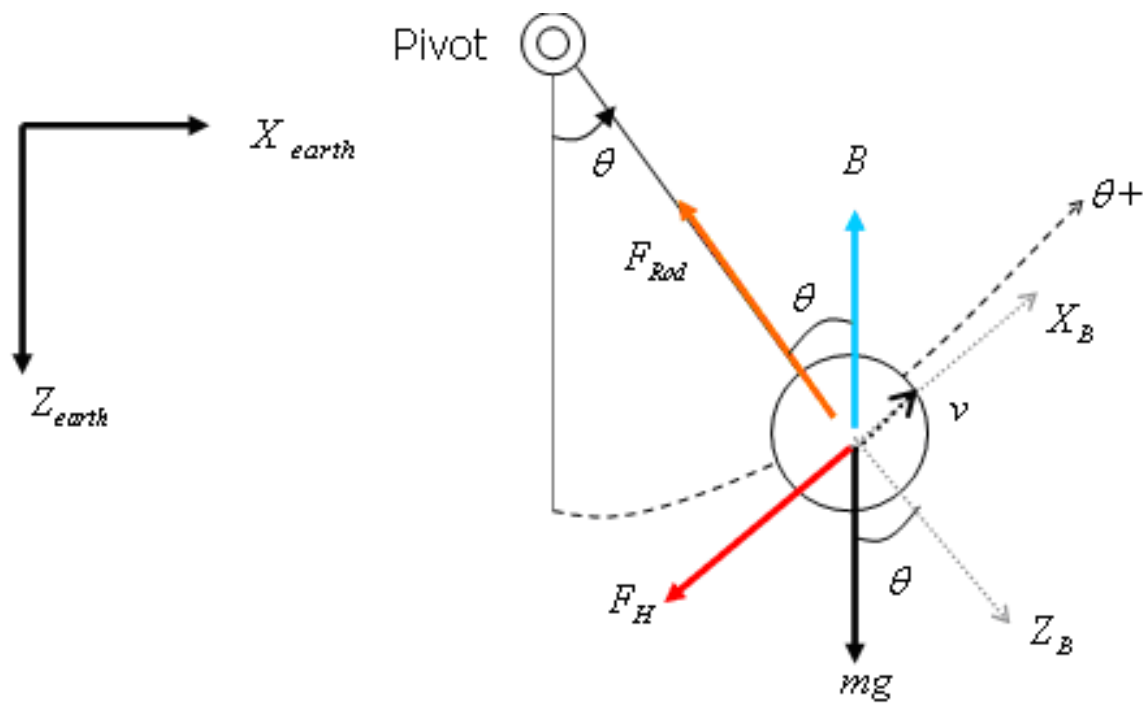

Fig. 2 Free Body Diagram of the Pendulum under Hydrodynamics Forces 
In the earth-fixed frame, the obj ect is rotating about the pi vot point. However, in the bodyfixed frame, the object only moves in the surge direction at any instance; the object has only velocity component in surge direction.

The added mass and the damping coefficient are defined in body fixed frame such that,

$$
F_{H}=m_{a} \ddot{x}+K_{L} \dot{x}+K_{Q}|\dot{x}| \dot{x}
$$

The equation of motion in the srge direction using Newton's second law of motion:

$$
\begin{gathered}
\sum F=M \ddot{x} \\
-M g \sin \theta+B \sin \theta-m_{a} \ddot{x}-K_{L} \dot{x}-K_{Q}|\dot{x}| \dot{x}=M \ddot{x}
\end{gathered}
$$

Rearranging equation (3) gives:

$$
\begin{gathered}
(B-M g) \sin \theta-K_{L} \dot{x}-K_{Q}|\dot{x}| \dot{x}=\left(M+m_{a}\right) \ddot{x} \\
\ddot{\mathrm{x}}=\frac{(\mathrm{B}-\mathrm{Mg})}{\left(\mathrm{M}+\mathrm{m}_{\mathrm{a}}\right)} \sin \theta-\frac{\mathrm{K}_{\mathrm{L}}}{\left(\mathrm{M}+\mathrm{m}_{\mathrm{a}}\right)} \dot{\mathrm{x}}-\frac{\mathrm{K}_{\mathrm{Q}}}{\left(\mathrm{M}+\mathrm{m}_{\mathrm{a}}\right)}|\dot{\mathrm{x}}| \dot{\mathrm{x}}
\end{gathered}
$$

For rotational motion, $\dot{x}=r \dot{\theta}$ and $\ddot{x}=r \ddot{\theta}$

$$
\begin{aligned}
r \ddot{\theta} & =\frac{(B-M g)}{\left(M+m_{a}\right)} \sin \theta-\frac{K_{L}}{\left(M+m_{a}\right)} r \dot{\theta}-\frac{K_{Q}}{\left(M+m_{a}\right)} r \dot{\theta}|r \dot{\theta}| \\
\ddot{\theta} & =\frac{(B-M g)}{\left(M+m_{a}\right) r} \sin \theta-\frac{K_{L}}{\left(M+m_{a}\right)} \dot{\theta}-\frac{K_{Q} \cdot r}{\left(M+m_{a}\right)} \dot{\theta}|\dot{\theta}| \\
\text { Let } \quad \alpha & =\frac{(\mathrm{B}-\mathrm{Mg})}{\left(\mathrm{M}+\mathrm{m}_{\mathrm{a}}\right) \mathrm{r}}, \beta=\frac{\mathrm{K}_{\mathrm{L}}}{\left(\mathrm{M}+\mathrm{m}_{\mathrm{a}}\right)} \quad \text { and } \gamma=\frac{\mathrm{K}_{Q} \cdot \mathrm{r}}{\left(\mathrm{M}+\mathrm{m}_{\mathrm{a}}\right)}
\end{aligned}
$$$$
\text { Then } \quad \ddot{\theta}=\alpha \cdot \sin \theta-\beta \cdot \dot{\theta}-\gamma \cdot \dot{\theta}|\dot{\theta}|
$$

\section{Least Square}

Using least square method [11] to obtain the estimated $\alpha, \beta, \gamma$

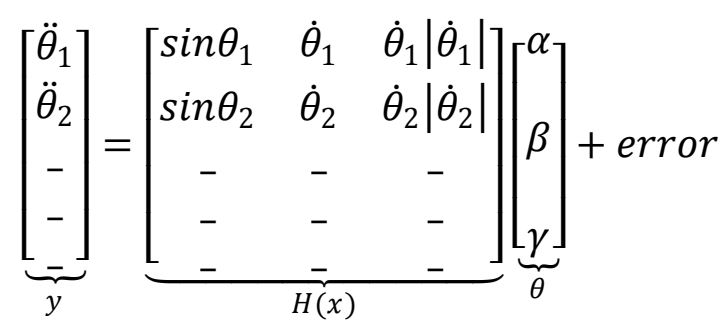

Subscript $i=1,2,3 \ldots$ represent the number of samples collected from the experiment

Result,

$$
\dot{\theta}_{L S}=\left(H^{T} H\right)^{-1} H^{T} y
$$




\section{Experimental Setup}

The experimental setup is simple and the costs involved are minimal. The setup is shown in Fig. 3. T he m odel of the $\mathrm{R} \mathrm{OV}$ i s a ttached $\mathrm{t} o$ one e nd of a pe ndulum in the w ater $\mathrm{t}$ ank $(1 \mathrm{~m} \times 2 \mathrm{mx} 1 \mathrm{~m})$ and the other end of the pendulum was equipped with an indicator so that the motion can be captured by a digital camera.

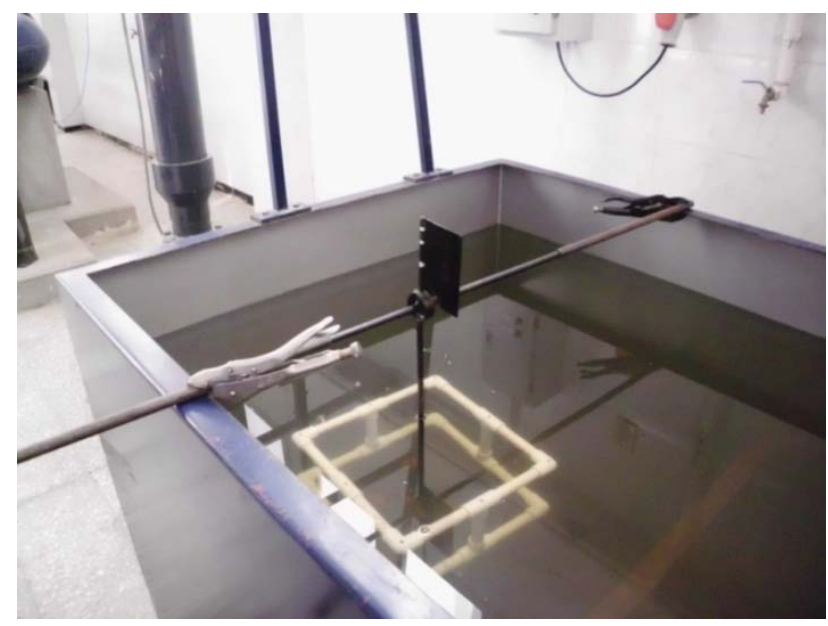

Fig. 3 Experiment setup

First, put a small white mark on the indicator. Next, attach the fixture to the structure of the water tank with a ball bearing as shown in Fig. 3. Set the camera up to capture the trajectory of the white mark when pendulum is swinging. The white mark must distinguish itself from its ba ckground f or e ase of i mage pr ocessing. After that, di splace the pe ndulum from $i$ ts equilibrium, up to a pproximate 30 degrees and then release it to swing freely in the water. Record the trajectory of the white mark using the video camera. Then, download the recorded video into PC and use a covariant tracking MATLAB ${ }^{\mathrm{TM}}$ program to locate the coordinates of the white marker. Next, the time history of $\theta$ is determined from the $\mathrm{x}$ and $\mathrm{y}$ coordinates. Finally, apply the least s quare a lgorithm to $\mathrm{c}$ alculate the a dded mass, 1 inear da mping and qua dratic damping $\left(\mathrm{m}_{\mathrm{a}}, \mathrm{K}_{\mathrm{L}}, \mathrm{K}_{\mathrm{Q}}\right)$.

The same procedures will be done in surge, heave and sway directions. In our particular case the model is symmetric so the surge and sway directions are the same.

For rotational damping coefficients the similar setup is used but the pendulum effect is done by a torsion spring with known torsion spring constant $\mathrm{K}_{\mathrm{t}}$. then the equation will be

$$
\ddot{\theta}=\frac{\mathrm{K}_{\mathrm{t}}}{\left(I+I_{a}\right)} \theta-\frac{K_{L}}{\left(I+I_{a}\right)} \dot{\theta}-\frac{K_{L}}{\left(I+I_{a}\right)}|\dot{\theta}| \dot{\theta}
$$

where $\mathrm{I}$ is the moment of inertia, $\mathrm{I}_{\mathrm{a}}$ is the added moment of inertia

\section{Covariance Tracking}

A s imple and e legant a lgorithm to track non -rigid obj ects us ing a covariance based object description a nd an upd ate $m$ echanism $b$ ased on m eans on $R$ iemannian manifolds [9]. A $n$ object $\mathrm{w}$ indow, Fig. 4, is $\mathrm{r}$ epresented as $\mathrm{t}$ he $\mathrm{c}$ ovariance $\mathrm{m}$ atrix of $\mathrm{f}$ eatures; $\mathrm{t}$ herefore $\mathrm{w} \mathrm{e}$ manage to capture the spatial and statistical properties as well as their correlation within the same $r$ epresentation. The cova riance $m$ atrix ena bles ef ficient fusion of different $t$ ypes of features a nd $\mathrm{m}$ odalities, a nd $\mathrm{i}$ ts di mensionality is $\mathrm{s}$ mall. $\mathrm{W}$ e i ncorporated a model upd ate algorithm us ing the elements of R iemannian geometry. The upda te m echanism ef fectively 
adapts $\mathrm{t} \mathrm{o} t$ he unde rgoing obj ect de formations a nd a ppearance $\mathrm{c}$ hanges. $\mathrm{T}$ he $\mathrm{c}$ ovariance tracking method does not make any assumption on the measurement noise and the motion of the tracked objects, and provides the global optimal solution. We show that it is capable of accurately detecting the non-rigid, moving objects in non-stationary camera sequences while achieving a promising detection rate of 97.4 percent.

\section{Results and Discussion}

The captured swinging video was ( 30 frames per second), so the time interval between each frame is $1 / 30$ second. The angle $\theta$ versus time is plotted in Fig. 5.

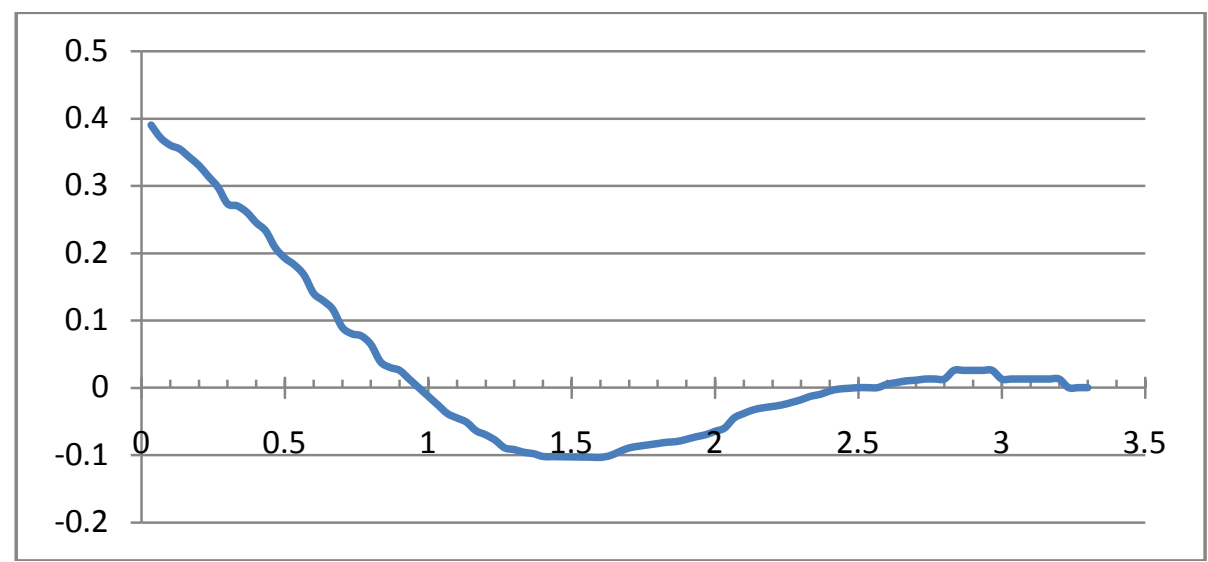

Fig. 5 Angle $(\theta)$ vs. time

Table (1) presents sample of values of $(\theta),(\dot{\theta})$ and $(\ddot{\theta})$ versus time, these values are then used in equations $(6,8)$ to determine the values of $\left(\mathrm{m}_{\mathrm{a}}, \mathrm{K}_{\mathrm{L}}\right.$ and $\left.\mathrm{K}_{\mathrm{Q}}\right)$.

Table (2) $(\boldsymbol{\theta}, \dot{\theta}$ and $\ddot{\theta})$ versus time

\begin{tabular}{c|c|c|c}
\hline \hline Time $[\mathrm{s}]$ & $\theta[\mathrm{rad}]$ & $\dot{\theta}[\mathrm{rad} / \mathrm{s}]$ & $\ddot{\theta}\left[\mathrm{rad} / \mathrm{s}^{2}\right]$ \\
\hline \hline 0.033333 & 0.389918 & -0.23847 & -1.14786 \\
0.066667 & 0.370891 & -0.27673 & -1.03656 \\
0.1 & 0.36 & -0.31128 & -0.9292 \\
0.133333 & 0.354259 & -0.34226 & -0.82576 \\
0.166667 & 0.342156 & -0.36978 & -0.72623 \\
0.2 & 0.33 & -0.39399 & -0.63058 \\
0.233333 & 0.313621 & -0.41501 & -0.53881 \\
0.266667 & 0.297562 & -0.43297 & -0.45087 \\
0.3 & 0.273009 & -0.448 & -0.36676 \\
0.333333 & 0.27 & -0.46022 & -0.28644 \\
0.366667 & 0.260602 & -0.46977 & -0.2099 \\
0.4 & 0.244979 & -0.47677 & -0.13709 \\
0.433333 & 0.232557 & -0.48134 & -0.06798 \\
0.466667 & 0.207496 & -0.4836 & -0.00255 \\
0.5 & 0.192396 & -0.48369 & 0.059236 \\
0.533333 & 0.182168 & -0.48171 & 0.117421 \\
0.566667 & 0.167254 & -0.4778 & 0.172042 \\
0.6 & 0.140102 & -0.47207 & 0.223138 \\
\hline \hline
\end{tabular}


The analysis of the data collected in 3 trails from the motion in surge direction produced the following data, Table (3).

Table (3) Results of three tests in surge direction

\begin{tabular}{c|c|c|c}
\hline \hline Test & $\begin{array}{c}\text { Added mass } \\
{[\mathrm{kg}]}\end{array}$ & $\begin{array}{c}\text { Linear damping coeff. } \\
{[\mathrm{N} /(\mathrm{m} / \mathrm{s})]}\end{array}$ & $\begin{array}{c}\text { Quadric damping coeff. } \\
{\left[\mathrm{N} /(\mathrm{m} / \mathrm{s})^{2}\right]}\end{array}$ \\
\hline \hline 1 & 22.55 & 16.88 & 48.15 \\
\hline 2 & 18.65 & 13.96 & 39.83 \\
\hline 3 & 20.29 & 15.19 & 43.33 \\
\hline Average & 20.50 & 15.34 & 43.77 \\
\hline \hline
\end{tabular}

The results from the CFX model Fig. (6) where the R OV model was s ubjected to variable speeds from 0.1 to $1 \mathrm{~m} / \mathrm{s}$, and the force then been calculated.

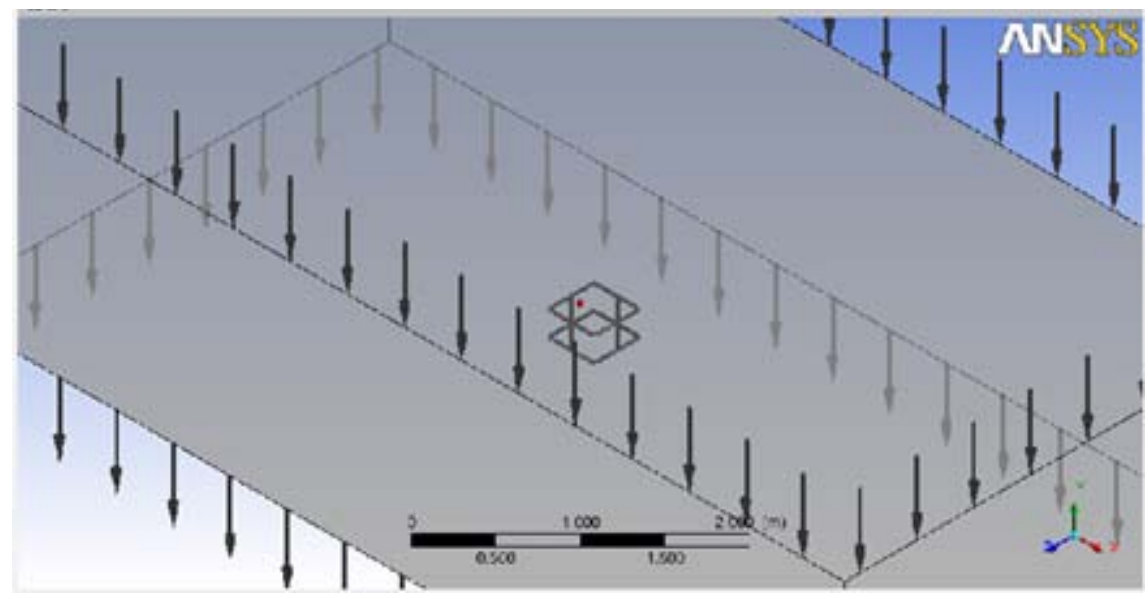

Fig. 6 CFX Model

The model was made upon a constant fluid velocity, so the coefficients calculated was linear and quadric damping coefficients on ly, while the added mass c ould not be calculated since there is no acceleration. The values of force versus velocity are shown in Table (4).

Table (4) Force vs. velocity in CFX model

\begin{tabular}{c|c}
\hline \hline Velocity $[\mathrm{m} / \mathrm{s}]$ & Force $[\mathrm{N}]$ \\
\hline \hline 0.1 & 1.933905 \\
\hline 0.2 & 4.698164 \\
\hline 0.3 & 8.462566 \\
\hline 0.4 & 12.97699 \\
\hline 0.5 & 18.34189 \\
\hline 0.6 & 24.55196 \\
\hline 0.7 & 32.13808 \\
\hline 0.8 & 40.31375 \\
\hline 0.9 & 48.93912 \\
\hline 1 & 57.84638 \\
\hline \hline
\end{tabular}


Depending on $\mathrm{t}$ he pr evious va lues, the 1 inear and quadric $\mathrm{d}$ amping coefficients ar e determined, Table (5)

Table (5) Coefficients calculated from CFX model

\begin{tabular}{l|l|l}
\hline \hline Linear damping coefficient & 13.5 & $\mathrm{~N} /(\mathrm{m} / \mathrm{s})$ \\
\hline Quadric damping coefficient & 38.5 & $\mathrm{~N} /(\mathrm{m} / \mathrm{s})^{2}$ \\
\hline \hline
\end{tabular}

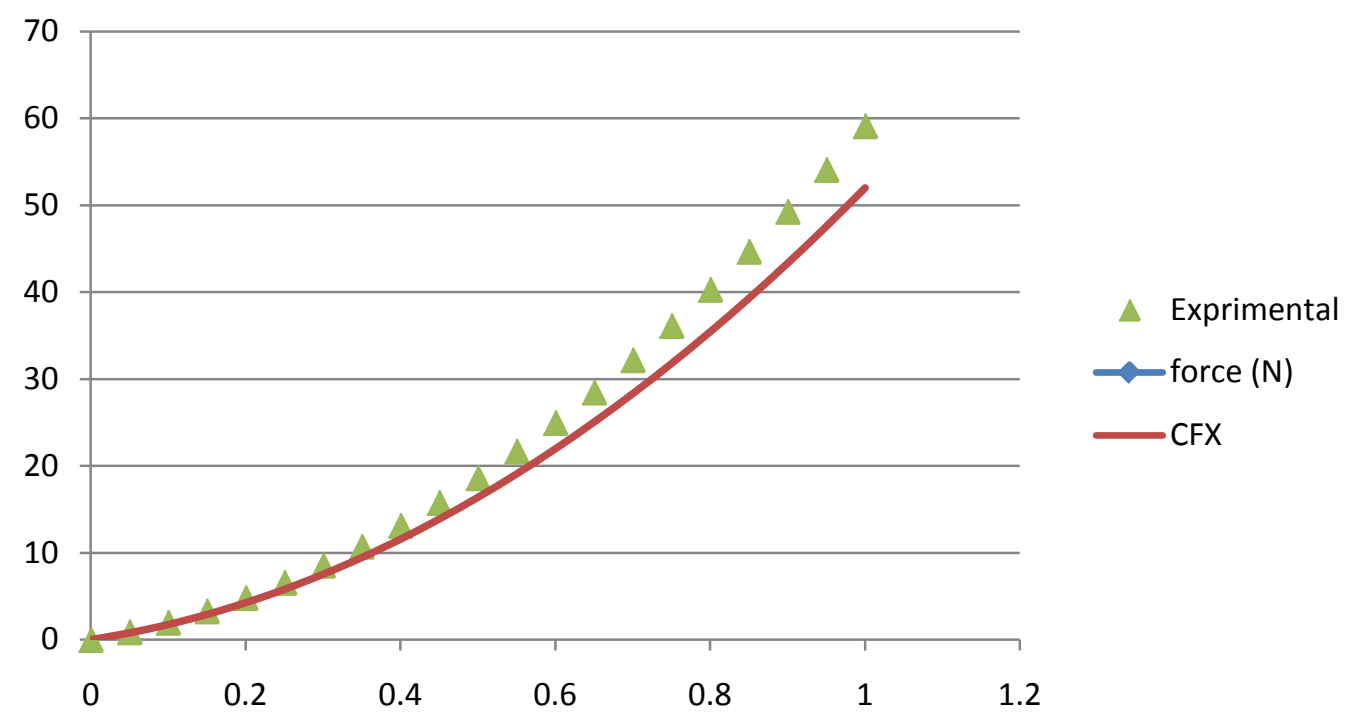

Fig. 7 Force vs velocity for experimental and CFX model

\section{Conclusion}

The us e of free de cay p endulum motion is a us eful and low cost m ethod to de termine the hydrodynamic $\mathrm{c}$ oefficients. In $\mathrm{t}$ his $\mathrm{m}$ odel the values of $\mathrm{c}$ oefficients va ried be tween $\mathrm{t}$ he experimental a nd $t$ he $\mathrm{C} \mathrm{FX} \mathrm{m}$ odel due $\mathrm{t}$ o e ffect of f riction i $\mathrm{n} t$ he ba $1 \mathrm{l}$ be aring, a nd $\mathrm{t}$ he inaccuracy of weight and dimensions measurements, Fig. 7.

The ex periment can be done a gain in s way and he ave di rections, a lso the torsion damping coefficient and added inertia could similarly be calculated.

The us e of covariant tracking can represent an accurate $m$ ethod to de termine the s winging angle.

\section{References}

[1]. P. Egeskov, A. Bjerrum, A. Pascoal, C. Silvestre, C. Aage, and L. W. S mitt, "Design, construction and hydrodynamic testing of the AUVMARIUS," Cambridge, MA, USA, 1994.

[2]. C. A age and L. W agner S mitt, "Hydrodynamic manoeuvrability dataof a flatfish type AUV," Brest, France, 1994.

[3]. Alessandri, R. B ono, M. C accia, G . Indiveri, a nd G . V eruggio, "Experiences on t he modelling and identification of the heave motion of an open-frame UUV," presented at Oceans Conference Record (IEEE), Nice, Fr, 1998. 
[4]. P. Ridao, A. Tiano, A. El-Fakdi, M. Carreras, and A. Zirilli, "On the identification of non-linear m odels of un manned unde rwater ve hicles," $\mathrm{C}$ ontrol E ngineering $\mathrm{P}$ ractice, vol. 12, pp. 1483-1499, 2004.

[5]. D. A . S mallwood a nd L. L. W hitcomb, "Adaptive i dentification o f d ynamically positioned unde rwater robotic ve hicles," IEEE T ransactions on C ontrol S ystems Technology, vol. 11, pp. 505-515, 2003.

[6]. T. Morrison, III and D. R. Yoerger, "Determination of the hydrodynamic parameters of an unde rwater ve hicle during s mall s cale, nonuniform, 1 -dimensional t ranslation," Victoria, BC, Canada, 1993.

[7]. T. I. F. A . R oss, a nd T . A . J ohansen, " Identification of underwater v ehicle hydrodynamic c oefficients us ing f ree de cay t ests," IFAC C onference on C ontrol Applications in Marine Systems, Ancona, Italy, 2004.

[8]. Eng YH, Lau WS, Low E., Seet GGL and CS Chin, "Estimation of the Hydrodynamics Coefficients of an ROV using Free Decay Pendulum Motion," the School of Mechanical \& Aerospace Engineering (MAE), china, 2008.

[9]. Fatih Porikli, Oncel T uzel, Peter M eer, "Covariance T racking using M odel U pdate Based on Means on Riemannian Manifolds," Mitsubishi Electric Research Laboratories, Cambridge, 2007. 